\title{
Determinación de la actividad endo-proteolítica en cebada malteada
}

\section{Endoproteolytic activity assay in malting barley}

\author{
Gómez Guerrero, Blanca (1), Edney, Michael J. ( ${ }^{(2)}$ \\ (1) Departamento de Cereales, Oleaginosos y Productos Derivados, Laboratorio Tecnológico del Uruguay, LATU, \\ Uruguay - ${ }^{(2)}$ Applied Barley, Grain Research Laboratory, Canadian Grain Commission, Winnipeg, Canadá. \\ Contacto: bgomez@latu.org.uy
}

Recibido: 15/6/2012 - Aprobado: 25/7/2013

\begin{abstract}
$\underline{\text { Resumen }}$
La hidrólisis de las proteínas de cebada en péptidos y aminoácidos es uno de los procesos más importantes en la germinación de la cebada. La degradación de las proteínas de reserva del endosperma promueven tanto el aumento de la concentración de nitrógeno amínico como la modificación del endosperma, facilitando la movilidad del agua y, por ende, de las enzimas. La actividad proteolítica es el resultado de actividades conjuntas de exo- y endo-peptidasas. Las proteínas de cebada son solubilizadas inicialmente por las endo-peptidasas y luego por las exo-peptidasas. Se han descrito cuatro tipos de endo-peptidasas: serin, cisteín, aspartic y metalo. El objetivo del trabajo consistió en la puesta a punto de un método enzimático para determinar la actividad endo-proteolítica de estas cuatro enzimas, utilizando un método rápido, colorimétrico, con dos sustratos diferentes: azo-gelatina y azo-caseína. Se optimizaron las condiciones de ensayo: pH, tiempo y temperatura de reacción. El sustrato azo-gelatina presentó varias dificultades para estandarizar un método colorimétrico que sea reproducible. En cambio, el sustrato azo-caseína fue muy consistente y permitió realizar las curvas de estandarización para las cuatro enzimas. Luego el método se aplicó exitosamente para la determinación de la actividad endo-proteolítica en cebada, malta y mosto cervecero.

Palabras clave: Endo-peptidasas, malta, proteólisis.
\end{abstract}

\begin{abstract}
$\underline{\text { Abstract }}$
Hydrolysis of barley proteins into peptides and amino acids is one of the most important processes during barley germination. The degradation of the endosperm stored proteins facilitates water and enzyme movements, enhances modification, liberates starch granules and increases soluble amino nitrogen. Protease activity is the result of the activities of a mixture of exo- and endo-proteases. The barley proteins are initially solubilized by endo-proteases and the further by exo-proteases. Four classes of endo-proteases have been described: serine-proteases, cysteine-proteases, aspartic-proteases and metallo-proteases. The objective of this work was to develop a rapid and colorimetric enzymatic assay to determine the endo-proteolytic activity of the four endo-protease classes using two different substrates: azo-gelatin and azo-casein. Optimum conditions for the assays such as: $\mathrm{pH}$, reaction time and temperature and absorbance scale were determined. Azo-gelatin presented several difficulties in standardizing an "in solution" assay. On the other hand, azo-casein allowed standardization of the assay for the four enzyme classes to produce consistent results. The endo-proteoteolytic method developed was applied to determine the endo-protease activity in barley, malt and wort.

Keywords: Endoproteases, malt, proteolysis.
\end{abstract}

\section{Introducción}

La cebada es uno de los cultivos de mayor difusión en el mundo y la cebada malteada (malta) utilizada como materia prima en las cervecerías y destilerías es el producto de mayor valor agregado. A medida que los procesos en las cervecerías se vuelven automáticos, se hace preciso conocer el comportamiento esperado de cada variedad de cebada previo a su procesamiento en la industria. En la actualidad, nuevas variedades de malta deben alcanzar las especificaciones de calidad requeridas por el mercado regional e internacional. Es por esto que son necesarios nuevos métodos analíticos que permitan determinar características del perfil de calidad de una malta.

Las endopeptidasas son las enzimas responsables de la hidrólisis de las proteínas de reserva, en péptidos y aminoácidos, durante el proceso de malteo en la maltería y el macerado en la cervecería
(Briggs, 1998). Si esta hidrólisis ocurre en una baja tasa, habrá insuficientes compuestos nitrogenados de bajo peso molecular en el mosto para una óptima nutrición de la levadura. Por el contrario, una hidrólisis excesiva deja al mosto sin las proteínas necesarias para la formación de la espuma y el cuerpo de la cerveza (Jones, 2008).

La actividad proteolítica es el resultado de un complejo mix de actividades de exo- y endopeptidasas. Las proteínas de cebada son inicialmente solubilizadas por las endopeptidasas y luego por las exopeptidasas. La mayoría de las proteasas actúan en el interior de la cadena peptídica (endopeptidasas) o en su extremo terminal (exopeptidasas) (Palma et al., 2002).

Las endopeptidasas son clasificadas de acuerdo al mecanismo catalítico, el cual implica la especificidad del sitio activo de la enzima. Es importante mencionar que el término endopeptidasas es igual a endoproteinasas. En la cebada se han descrito cuatro tipos de endoproteasas: serin-proteinasas (EC 3.4.21), cisteín-proteinasas (EC 
3.4.22), aspartic-proteinasas (EC 3.4.23) y metalo-proteinasas (EC 3.4.24) (Palma et al., 2002).

El grupo de proteasas de cebada que ha sido más estudiado son las cisteín endopeptidasas. El mecanismo catalítico de estas enzimas incluye un grupo cisteín en el sitio activo. Su rol principal es la movilización de las proteínas durante la germinación. La familia de la papaína es la más investigada. Estas enzimas se sintetizan como zimógenos, por lo cual que requieren un agente reductor para activarse (Koehler y Ho, 1990).

Las serin endoproteasas son proteasas neutras que tienen en el sitio activo el aminoácido serina. En la cebada, la mayoría de la actividad serin-peptidasas se encuentra en las raíces y tallos, con algo de actividad en el endosperma del grano (Zhang y Jones, 1995b). La enzima tripsina pertenece a la familia de las serin peptidasas.

Aspartic endopeptidasas presentan preferencias por los enlaces peptídicos que se encuentran rodeados con residuos aminoacídicos hidrofóbicos, por lo cual son activas a $\mathrm{pH}$ ácidos. Si bien en la cebada esta clase de enzima es abundante, se le ha prestado poca atención y todavía se sabe poco de su función biológica (Jones, 2005a).

Las metalo proteasas son el grupo menos conocido dentro de las endopeptidasas de cebada. La mayoría de estas enzimas contienen zinc en su sitio activo, aunque cobalto y manganeso también pueden estar presentes para activar la enzima. Las metalo proteasas han sido detectadas en todos los tejidos del grano de cebada; la capa de aleurona es la que presenta la mayor concentración (Jones, 2005b).

Zhang y Jones $(1995 \mathrm{a}, \mathrm{b})$ caracterizaron y clasificaron 42 actividades endopeptidasas diferentes en granos de cebada germinados basándose en los valores del punto Isoeléctrico, en la movilidad en geles de dos dimensiones y características bioquímicas. Este método permitió separar las 42 actividades en puntos individuales de actividad, de los cuales 27 pertenecían al tipo cisteín, siete al tipo serin, cuatro al tipo metalo y cuatro al tipo aspartic. Este importante número de peptidasas, que incluyen algunas isoformas, no incluyen a las exopeptidasas. El aporte relevante de la técnica de geles en dos dimensiones es que dentro de cada tipo de proteasas los miembros individuales presentaron un $\mathrm{pH}$ óptimo similar, y entre los diferentes tipos se encontraron diferencias. Los tipos cistein y aspartic mostraron mayor actividad a valores de $\mathrm{pH}$ entre 4,8 y 4,5 , mientras que los tipos serin y metalo fueron activas a niveles de $\mathrm{pH}$ óptimo alrededor de 6,0 y 8,5, respectivamente (Zhang y Jones, 1995a).

Algunos estudios han identificado QTL (quantitative trait loci) relacionados con la actividad proteasa y la calidad de malta, a pesar de que los detalles sobre los procesos implicados todavía no son claros (Kihara et al., 2006; Potokina et al., 2006). Las actividades de las endopeptidasas en cebada y malta han sido determinadas principalmente por dos tipos de metodologías: ensayos en solución y ensayos en geles de dos dimensiones. Estas metodologías han sido aplicadas con varios tipos de sustratos y condiciones $(\mathrm{pH}$, temperatura de reacción y tiempo de reacción), por lo cual los resultados varían de gran manera y son difíciles de comparar.

Jones et al. (1998) definieron un sistema para estudiar el mix de actividades de las endopeptidasas de manera rápida, cuantitativa y eficiente. El ensayo utiliza un sustrato proteico coloreado, azogelatina. El principio básico del método es mezclar el sustrato proteico con las endopeptidasas, remover fracciones a tiempos determinados y precipitar el sustrato no hidrolizado con ácido tricloroacético (TCA) y luego medir la absorbancia a $440 \mathrm{~nm}$. El estudio demostró que varias endopeptidasas presentaron un comportamiento lineal por 30 min o menos. Si bien los cuatro tipos de endopeptidasas mencionadas hidrolizan azogelatina, las endopeptidasas aspárticas lo hacen a una velocidad más lenta.

El sustrato azogelatina tiene excelentes atributos: 1) Es una proteína, lo cual permite tener una visión realista de cómo la enzima actúa sobre un sustrato natural. 2) Es hidrolizada por todas las clases de endoproteasas, aunque las aspárticas son las que lo hidrolizan en menor nivel. 3) Los productos de hidrólisis son coloreados y absorben a $440 \mathrm{~nm}$, eliminando el problema de interferencia con la absorción de los péptidos a $280 \mathrm{~nm}$. 4) Es soluble para un rango de $\mathrm{pH}$ entre 3 y 10,5 , en el cual se encuentran los pH óptimos de las cuatro clases de endoproteasas. 6) Precipita frente al TCA, permitiendo de esta manera cortar la reacción.

Osman (2003) utilizó un sustrato preparado directamente de la cebada, llamado fracción proteica de cebada altamente degradable (HDBPF - Highly Degradable Barley Protein Fraction) para medir la actividad endopeptidasa de la malta. Jones (2005a) concluyó que las propiedades de HDBPF como sustrato no eran apropiadas para el análisis de endopeptidasas, como sí lo es azogelatina.

Yano et al. (2008) utilizaron caseína como sustrato e inhibidores de las distintas clases de proteasas para determinar la actividad de las endo proteasas de malta y cebada usada como adjunto cervecero.

Schmitt y Budde (2007) desarrollaron un método fluorogénico para estimar la actividad de las endoproteasas de malta en grandes sets de muestras, especialmente para poblaciones de mapeo de los programas de mejoramiento genético. El pH del método se ajustó de manera de favorecer la actividad cisteín y serin. El uso de sustrato fluorogénico simplifica en gran medida el ensayo, lo que hace posible analizar una mayor cantidad de muestras.

En muchos estudios investigadores han utilizado sustratos como azocaseína, caseína y hemoglobina, que precipitan adecuadamente en presencia de TCA y son útiles para cuantificar endopeptidasas de malta. Sin embargo, estos sustratos son hidrolizados por algunas proteasas y en diferente tasa de hidrólisis.

Debido a esto, el objetivo del trabajo consistió en la puesta a punto de un método enzimático para determinar la actividad endoproteolítica de los cuatro tipos de endopeptidasas, aplicando un método rápido, colorimétrico, con dos sustratos diferentes: azo-gelatina y azo-caseína.

\section{Materiales y Métodos}

\section{Cebada y malta}

Las muestras de cebada y malta utilizadas en el estudio fueron proporcionadas por el laboratorio Barley Applied del Canadian Grain Commission. Las variedades utilizadas fueron AC Metcalfe, Harrington, AC Madi y MUSA 936.

\section{Elaboración de mosto cervecero}

Se realizó un mosto cervecero siguiendo la norma EBC método 4.5.1.

\section{Enzimas puras}

Se utilizaron como estándar las enzimas: papaína de carica papaya (Fluka -76218) EC 3.4.22.3; tripsina tipo III de páncreas bovino (Sigma T-8253) EC 3.4.21.4; pepsina A de mucosa estomacal de porcino (Sigma P-7000) EC 3.4.23.1, y proteasa tipo IX proveniente de Bacillus polymyxa (Sigma P6141) EC.3.4.24. Todas las soluciones estándar de las enzimas se prepararon disolviendo $1 \mathrm{mg}$ de la enzima pura en $1 \mathrm{ml}$ de agua ultra pura. Los buffers de reacción y dilución utilizados con las enzimas fueron: buffer acetato de amonio $0,1 \mathrm{M} \mathrm{a} \mathrm{pH}$ 4,8 y a pH 4,5 ; buffer citrato de sodio $0,1 \mathrm{M}$ a pH 6,0 ; buffer fosfato de sodio $0,1 \mathrm{M} \mathrm{pH} 7,0$.

\section{Ensayo con el sustrato azogelatina}

El sustrato azogelatina se sintetizó siguiendo los pasos descritos por Jones et al. (1998). Se preparó una solución del sustrato al $1 \% \mathrm{~m} / \mathrm{v}$ en buffer citrato de sodio a pH 6,0, el sustrato se termostatizó a $40{ }^{\circ} \mathrm{C}$ previo a su uso. La solución permaneció estable por varias semanas, manteniéndose a $4^{\circ} \mathrm{C}$

La extracción enzimática se realizó mezclando $0,38 \mathrm{~g}$ de harina de malta en $1,5 \mathrm{~mL}$ de buffer citrato de sodio a $\mathrm{pH} 6,0$, a $4{ }^{\circ} \mathrm{C}$ por 30 min. La preparación fue luego centrifugada a $14000 \mathrm{rpm}$ por $20 \mathrm{~min}$. 
Se separó el sobrenadante, el cual se utilizó para la reacción inmediata o se congeló a $-20^{\circ} \mathrm{C}$ para posterior análisis.

La reacción enzimática se llevo a cabo termostatizando por $10 \mathrm{~min}$ a $40{ }^{\circ} \mathrm{C} 670 \mu \mathrm{l}$ de extracción enzimática con $1670 \mu \mathrm{L}$ de buffer citrato de sodio a pH 6,0. La solución de azogelatina termostatizada (2200 $\mu 1)$ se adicionó a la solución enzimática y se vortexeó. Se removieron alícuotas de $600 \mu \mathrm{L}$ a tiempo 0 (blanco de reacción), y a los 10, 25, 45 y 60 min de reacción. Las alícuotas removidas fueron dispensadas a tubos que contenían $900 \mu \mathrm{L}$ de ácido tricloroacético (TCA) al 15\%, de manera de parar la reacción. El tubo se vortexeó y se incubó por 30 min en un baño de hielo. Las muestras se centrifugaron a $11500 \mathrm{~g}$ por $8 \mathrm{~min}$. Se determinó la absorbancia del sobrenadante a $440 \mathrm{~nm}$.

\section{Ensayo con el sustrato azocaseína}

El sustrato azocaseína fue provisto por Megazyme (S-AZCAS 12/2007). Se disolvió $1 \mathrm{~g}$ de sustrato en $2 \mathrm{~mL}$ de etanol. Luego se adicionaron $48 \mathrm{~mL}$ de buffer citrato de sodio a pH 6,0. La solución se almacenó y permaneció estable a $4^{\circ} \mathrm{C}$ por varias semanas.

La extracción enzimática se realizó suspendiendo $1 \mathrm{~g}$ de malta o

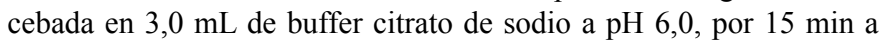
temperatura ambiente, vortexeando cada $5 \mathrm{~min}$. Luego se centrifugó por $15 \mathrm{~min}$ a $12000 \mathrm{~g}$. Se separó el sobrenadante, el cual se utilizó para la reacción inmediata o se congeló a $-20^{\circ} \mathrm{C}$ para posterior análisis.

La reacción enzimática se realizó termostatizando por 10 min $440^{\circ} \mathrm{C}$ $415 \mu \mathrm{L}$ de extracción enzimática con $319 \mu \mathrm{L}$ de buffer citrato de sodio y $100 \mu \mathrm{L}$ de L-Cisteína (Sigma C-7880) $10 \mathrm{mM}$. Se adicionaron al tubo de reacción $834 \mu \mathrm{L}$ de azocaseína termostatizada al $2 \%$. Se vortexeó y se dejó por $30 \mathrm{~min}$ a $40^{\circ} \mathrm{C}$. Se adicionaron $3,0 \mathrm{~mL}$ de TCA al $5 \%$ y se vortexeó vigorosamente por $5 \mathrm{seg}$. Los tubos de reacción permanecieron por $5 \mathrm{~min}$ a temperatura ambiente, se filtró con papel de filtro Whatman $\mathrm{N}^{\circ} 1$ y se midió absorbancia del filtrado a $440 \mathrm{~nm}$ contra el blanco de reacción.

El blanco de reacción se preparó adicionando 3,0 $\mathrm{mL}$ de TCA a un tubo con $100 \mu \mathrm{L}$ de Cisteína y $319 \mu \mathrm{L}$ de buffer citrato de sodio, se vortexeó $\mathrm{y}$, por último, se agregaron $415 \mu \mathrm{L}$ de la extracción enzimática.

\section{Resultados}

\section{Actividad proteolítica utilizando azogelatina como sustrato}

La enzima pura papaína se utilizó para realizar la curva de calibración y ajustar las condiciones del ensayo. Los resultados demostraron que la absorbancia a tiempo 0 (blanco de reacción) fue muy alta, con valores desde 0,332 a 0,386 , lo cual sugiere una baja estabilidad del sustrato a $40^{\circ} \mathrm{C}$. Las absorbancias obtenidas a los 10 , 25,45 y 60 min de reacción se presentan en el Gráfico 1. Debido a la falta de linealidad encontrada entre la absorbancia y la concentración de la enzima en las condiciones utilizadas, se decidió estudiar el comportamiento de la misma enzima a más altas concentraciones. Los resultados a altas concentraciones mostraron un comportamiento lineal.

Para fijar las condiciones de extracción se utilizaron dos maltas de diferentes variedades y se midió la absorbancia a los 10, 25, 45 y 60 min de reacción (Gráfico 2). La extracción de 15 min a temperatura ambiente para las dos variedades fue la que presentó resultados más consistentes.

La alta absorbancia de los blancos de reacción con azogelatina como sustrato se constató como un inconveniente, por lo que se realizaron varios ensayos de manera de reducir la absorbancia del blanco de reacción pero no se obtuvieron resultados exitosos.

De manera de probar la consistencia del método se ensayaron 10 muestras de malta de variedades diferentes y con distinto nivel de calidad maltera. Los resultados se muestran en el Gráfico 3, y se puede observar la inconsistencia del método, ya que para algunas maltas los valores de absorbancia a los 10 min de reacción fueron mayores que a los $25 \mathrm{~min}$, y en otras muestras se observó lo opuesto. También se esperaba que las variedades de menor calidad, basados en el nivel de nitrógeno amínico libre (muestra cercanas a la número 1), presentaran menor actividad endoproteolítica que las variedades con mayor calidad (muestras cercanas a la número 10) y esto tampoco se pudo observar en los resultados.

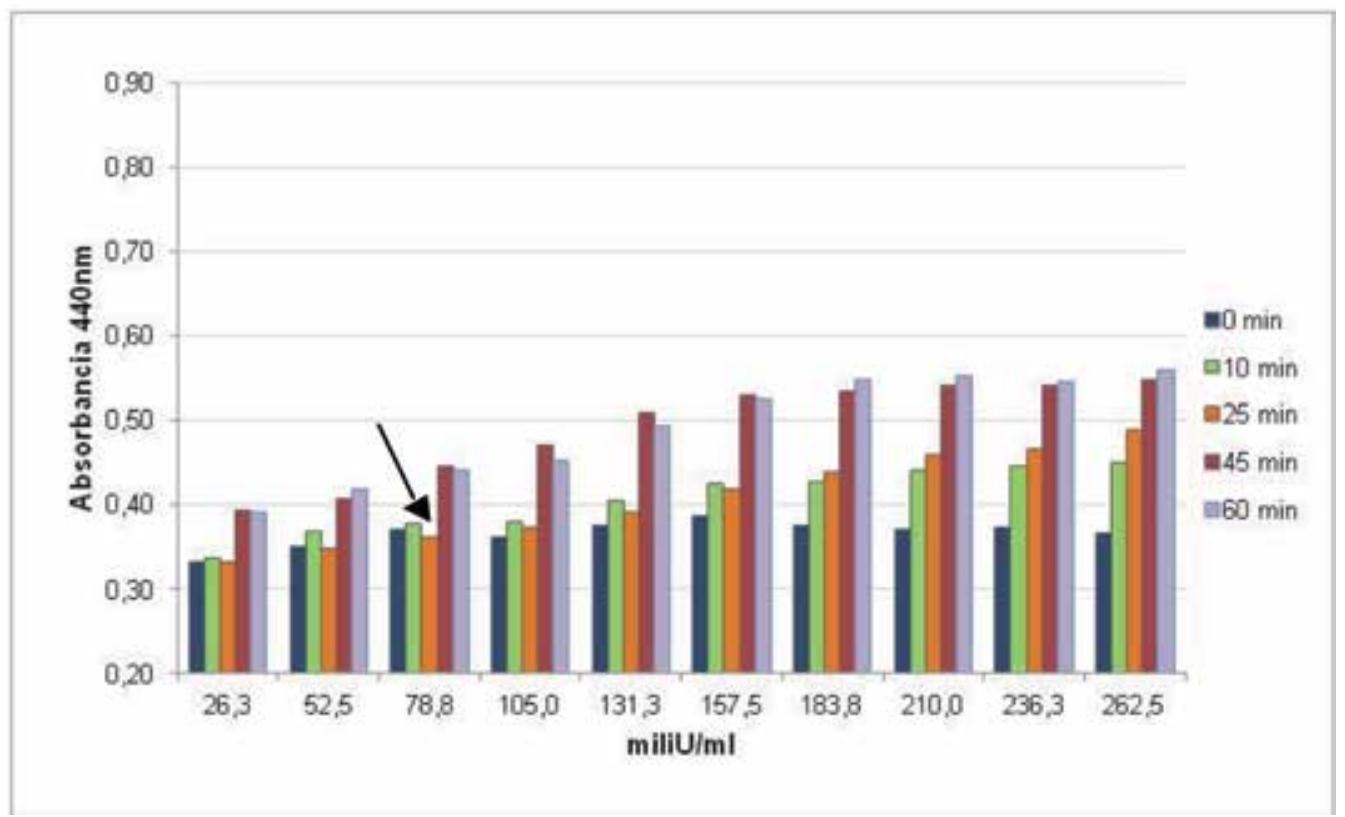

Gráfico 1. Actividad endoproteasa de la enzima papaína a bajas concentraciones, medida a partir del aumento de la absorbancia en un rango de tiempo de reacción. La flecha indica uno de los casos inesperados de baja absorbancia a $25 \mathrm{~min}$ de reacción. 


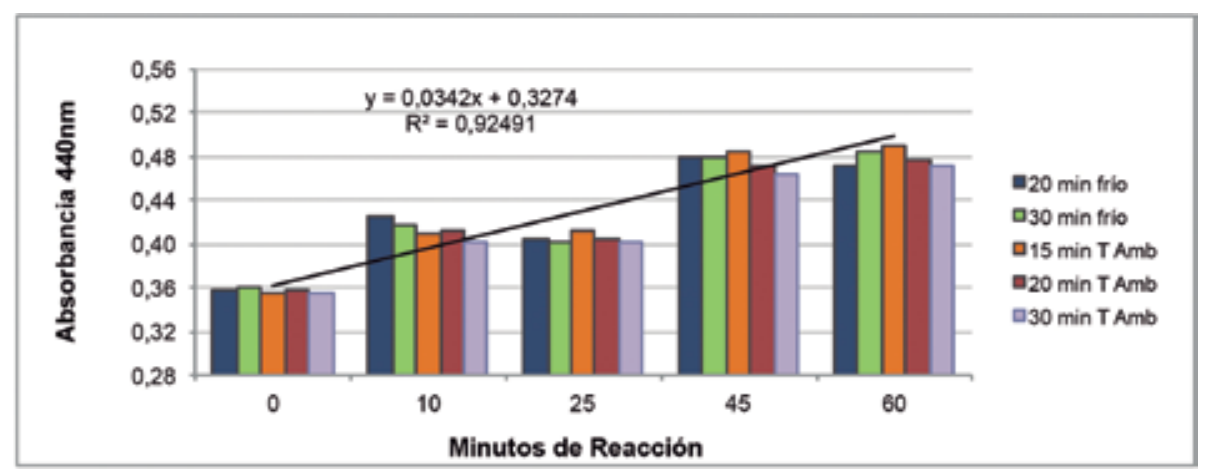

Gráfico 2. Actividad endoproteasa de malta variedad Harrington bajo diferentes condiciones de extracción, y medidas a través del aumento de la absorbancia en un rango de tiempo.

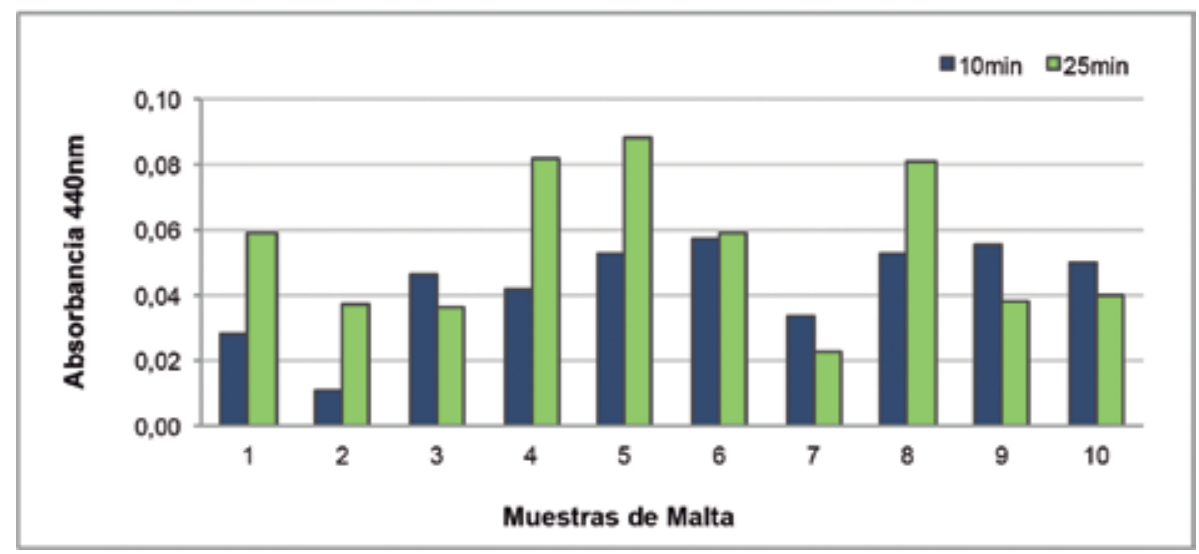

Gráfico 3. Actividad endoproteasa de maltas con distinta calidad maltera utilizando el sustrato azogelatina a pH 6,0. Muestras cercanas a 1 baja calidad, cercanas a 10 alta calidad.

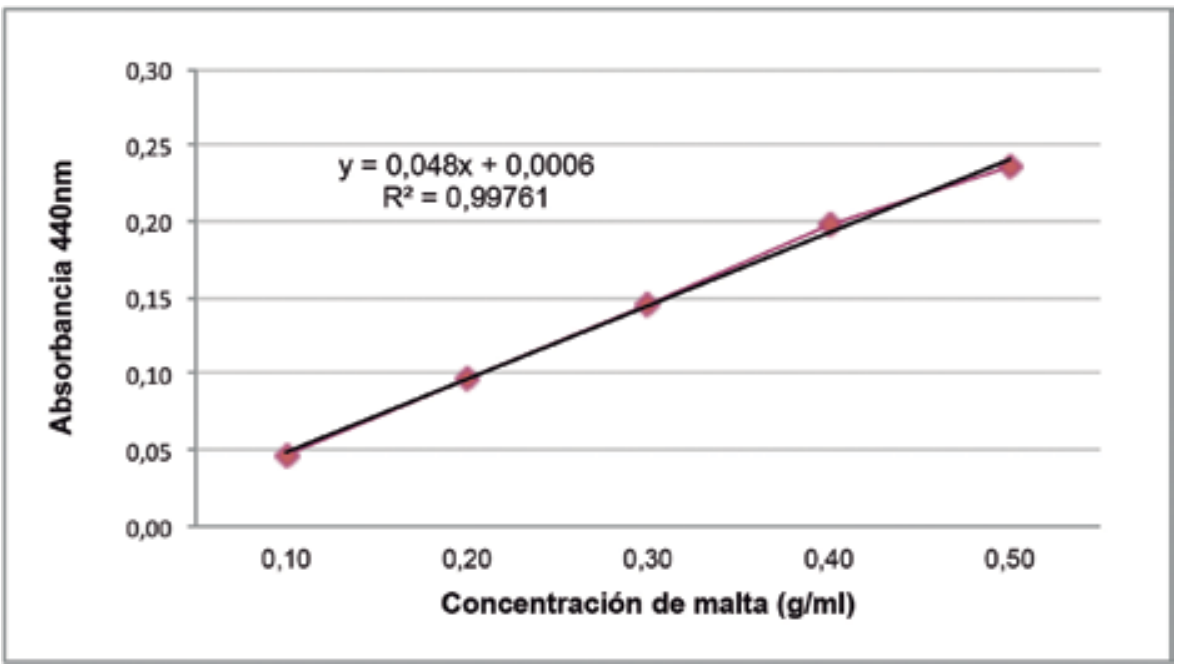

Gráfico 4. Actividad endoproteasa de malta utilizando el sustrato azocaseína a pH 6,0. 


\section{Actividad proteolítica utilizando azocaseína como sustrato}

Los resultados mostraron que utilizando el sustrato azocaseína se pueden obtener diferencias en los niveles de absorbancia para cada uno de los tipos de endoproteasas utilizadas como estándar (Tabla 1). Estos resultados demuestran la habilidad del sustrato para detectar diferentes clases de endoproteasas y cómo los cambios en el $\mathrm{pH}$ afectan la actividad endoproteolítica.

\begin{tabular}{|l|c|c|c|c|c|}
\hline \multirow{2}{*}{$\begin{array}{l}\text { Condiciones/ } \\
\text { Enzimas }\end{array}$} & \multicolumn{5}{|c|}{ Absorbancia 440nm - 10 min reacción } \\
\hline Buffer extracción & $\mathrm{pH} \mathrm{7,0}$ & $\mathrm{pH} 7,0$ & $\mathrm{pH} 5,5$ & $\mathrm{pH} 6,0$ & $\mathrm{pH} 6,0$ \\
\hline Buffer dilución & $\mathrm{pH} 7,0$ & $\mathrm{pH} 7,0$ & $\mathrm{pH} 7,0$ & $\mathrm{pH} 6,0$ & $\mathrm{pH} 6,0$ \\
\hline Volumen enzima & $100 \mu \mathrm{L}$ & $200 \mu \mathrm{L}$ & $100 \mu \mathrm{L}$ & $100 \mu \mathrm{L}$ & $100 \mu \mathrm{L}$ \\
\hline Adición cisteína & - & - & - & - & $2 \mathrm{mM}$ \\
\hline Proteasa & 0,074 & 0,766 & 0,498 & 0,007 & 0,010 \\
\hline Papaína & 0,067 & 0,073 & 0,024 & 0,050 & 2,672 \\
\hline Pepsina & 0,010 & 0,000 & 0,000 & 0,102 & 0,099 \\
\hline
\end{tabular}

Tabla 1. Absorbancia de las endoproteasas utilizando el sustrato azocaseína bajo diferentes condiciones de ensayo.

Así como se investigó el efecto del pH de los buffer utilizados para la extracción de las enzimas, también se estudió la relación entre la concentración de malta y el valor de la absorbancia. Los resultados muestran una excelente correlación lineal positiva para las concentraciones de malta estudiadas (Gráfico 4), a pesar de que los valores de absorbancia obtenidos no fueron muy elevados.

De manera de aumentar los valores de absorbancia de la malta diferentes condiciones de reacción fueron ensayadas (Tabla 2). Los resultados demostraron que las absorbancias aumentaron proporcionalmente con el aumento de las condiciones reductoras (adición de altas concentraciones de cisteína) para todas las concentraciones de malta ensayadas. A su vez, mayores tiempos de reacción ocasionaron mayores valores de absorbancia, con o sin la adición de cisteína. Por lo tanto, se seleccionó una combinación de adición de cisteína y tiempos de reacción, de manera de aumentar los valores de absorbancia y que estos se encuentren dentro del rango normal de absorbancia (desde 0,1 a 1,0 ).

Experimentos con diferentes tiempos de reacción (20 min y 40 min) y una adición de cisteína $25 \mathrm{mM}$ fueron ensayados utilizando las enzimas puras y extractos de malta con el fin de fijar las condiciones óptimas de reacción.

A partir de los resultados obtenidos se decidió investigar el efecto de disminuir la concentración de cisteína adicionada y determinar la actividad de las enzimas en una hora de reacción. Los resultados (Gráficos 5 y 6) demostraron que a pH 6,0 (el pH del mosto) y en condiciones reductoras (con adición de cisteína) la enzima que exhibió la mejor performance fue la papaína. Esta enzima presentó una relación lineal positiva significativa con la absorbancia durante una hora de reacción, aunque algunos de los valores de absorbancia se fueron de la escala normal (Gráfico 5A). La enzima proteasa (del tipo metalo) también presentó una relación lineal y positiva entre la absorbancia y el tiempo de reacción (Gráfico 5B), sin embargo los valores de absorbancia fueron menores en un rango más pequeño. La enzima pepsina, por su parte, no presentó un alto coeficiente de determinación (Gráfico 5C), lo cual indica que las condiciones de reacción no son las óptimas para determinar la actividad de las proteasas de clase aspartic. Para determinar si el sustrato azocaseína detectaba los cuatro tipos de endoproteasas se realizó una curva de calibración con la enzima tripsina (Gráfico 5D). Esta enzima presentó una alta asociación positiva entre la concentración y los valores de absorbancia, para valores de absorbancia mayores a 0,6.

Se midió la actividad endoproteolítica utilizando las condiciones descritas en el Gráfico 6 para tres maltas de diferente perfil de calidad maltera. Las medidas de absorbancia determinadas para un rango de reacción de una hora mostraron una relación lineal positiva con un alto valor de coeficiente de determinación. El tiempo de reacción se fijó en 30 min debido a que los valores de absorbancia obtenidos se encuentran en el medio del rango de absorbancia deseado.

De acuerdo a todos los resultados obtenidos se determinó adecuado el uso de la papaína como enzima pura para estandarizar el método y se construyó una curva de calibración (Gráfico 7). De la curva de calibración se extrajo la ecuación de regresión para utilizar en el cálculo de las unidades.

mU/ensayo $=[($ Abs 440nm - Blanco reacción $) * 143.1634]+22.74447$

Total $\mathbf{m U}=\left(\frac{\mathrm{mU} / \mathrm{ensayo}}{\text { Alicuota ensayada }(\mathrm{mL})}\right) *$ Volumen buffer de extrac. $(\mathrm{mL})$

$\mathrm{mU} / \mathrm{g}($ base seca $)=\left(\frac{\text { Total } \mathrm{mU}}{\text { Toma malta }(\mathrm{g})}\right) * \frac{1}{(100-\% \text { Humedad }) * 100}$

\begin{tabular}{|c|c|c|c|c|c|c|c|c|c|c|}
\hline \multicolumn{3}{|c|}{ Condiciones } & \multicolumn{4}{|c|}{ Reacción pH 6,0 } & & & & \\
\hline \multirow{2}{*}{$\begin{array}{c}\text { Conc. Malta } \\
\text { Tiempo Reac. }\end{array}$} & \multicolumn{2}{|c|}{$0,02(\mathrm{~g} / \mathrm{mL})$} & \multicolumn{4}{|c|}{$0,14(\mathrm{~g} / \mathrm{mL})$} & \multicolumn{4}{|c|}{$0,16(\mathrm{~g} / \mathrm{mL})$} \\
\hline & $10 \mathrm{~min}$ & $10 \mathrm{~min}$ & $10 \mathrm{~min}$ & $10 \mathrm{~min}$ & $10 \mathrm{~min}$ & $10 \mathrm{~min}$ & $10 \mathrm{~min}$ & $10 \mathrm{~min}$ & $25 \mathrm{~min}$ & $25 \mathrm{~min}$ \\
\hline Adición Cis. & - & $2 \mathrm{mM}$ & - & $2 \mathrm{mM}$ & $8,3 \mathrm{mM}$ & $25 \mathrm{mM}$ & - & $8,3 \mathrm{mM}$ & - & $8,3 \mathrm{mM}$ \\
\hline Abs. $440 \mathrm{~nm}$ & 0,011 & 0,017 & 0,063 & 0,099 & 0,116 & 0,138 & 0,072 & 0,127 & 0,151 & 0,260 \\
\hline
\end{tabular}

Tabla 2. Absorbancia de las endoproteasas de malta con azocaseína como sustrato, bajo diferentes condiciones de ensayo. 

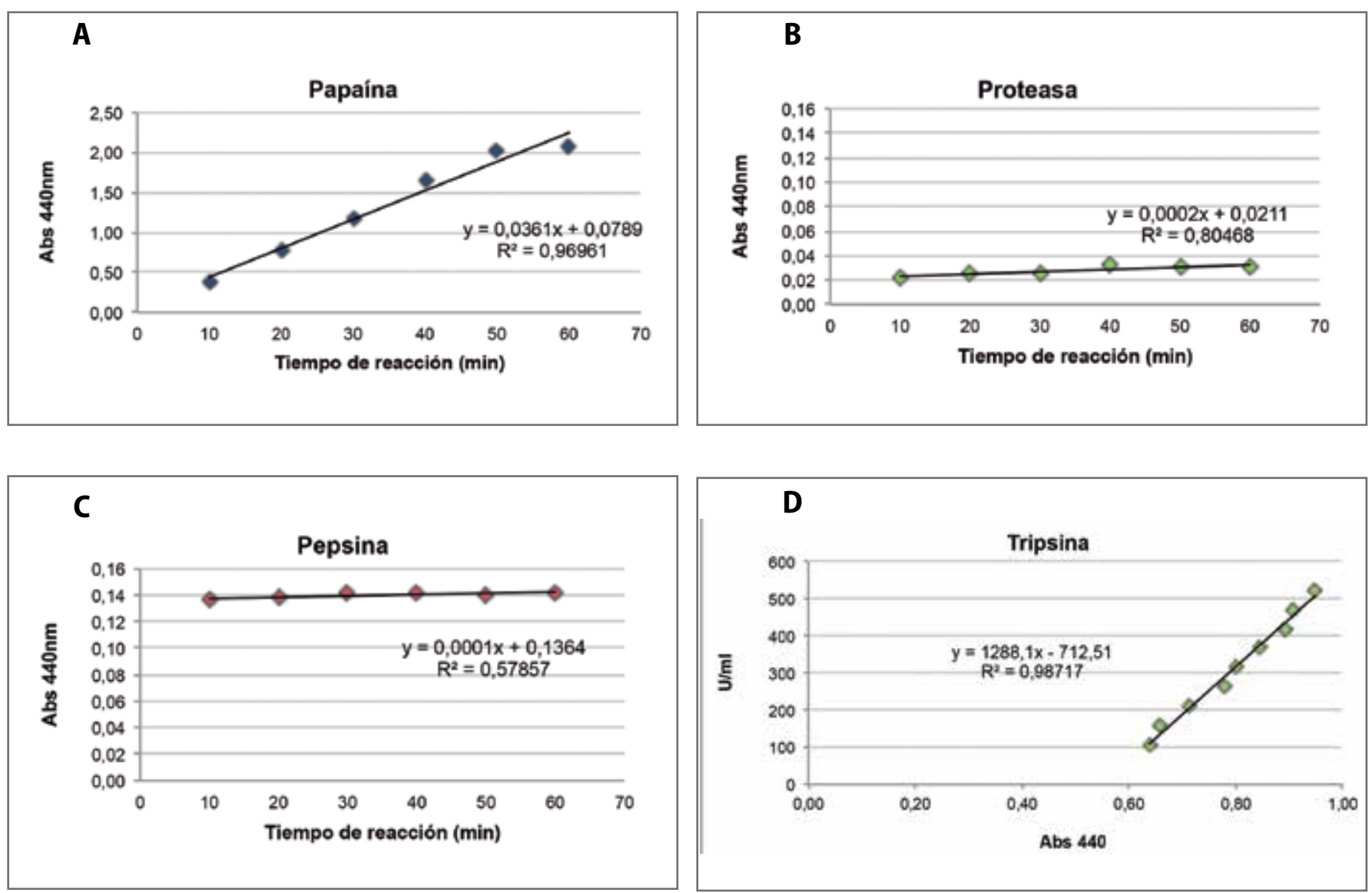

Gráfico 5. Absorbancia de las enzimas puras durante una hora de reacción. A) Tipo cisteína; B) Tipo Metalo; C) Tipo aspartic; D) Tipo Serin. Las condiciones de reacción fueron: Volumen de enzima: A) $20 \mu \mathrm{L}$; B) y C) $100 \mu \mathrm{L}$; azocaseína al 2\%, pH 6,0 y adición de cisteína $10 \mathrm{mM}$. D) Rango de concentración de la enzima utilizando azocaseína al 2\%, pH 6,0, adición de cisteína 10 mM por 30 min de reacción.

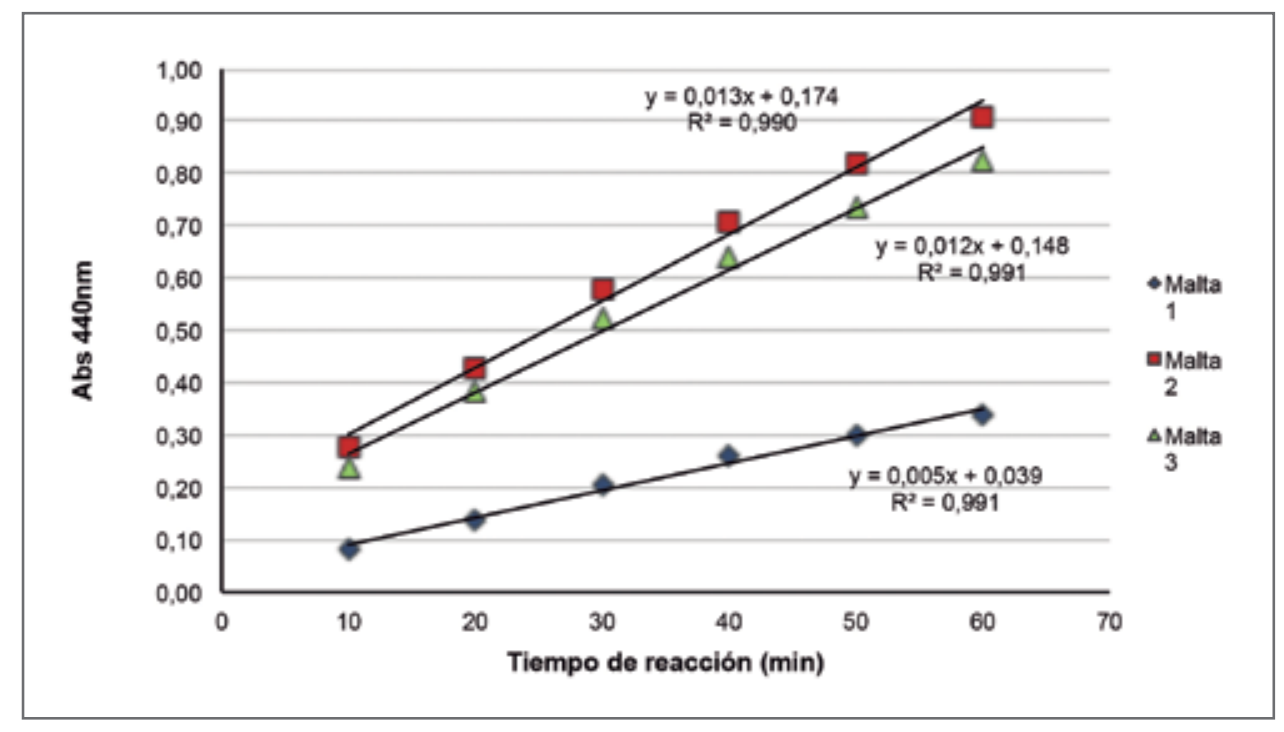

Gráfico 6. Absorbancia de las endoproteasas de tres variedades de malta con diferente perfil de calidad. Las condiciones de reacción fueron: concentración malta $0,33 \mathrm{~g} / \mathrm{mL}$; azocaseína al $2 \%, \mathrm{pH}$ 6,0 , adición de cisteína $10 \mathrm{mM}$ durante una hora de reacción. 
La reproducibilidad y repetibilidad de la cuantificación de la actividad endoproteolítica de malta se definió utilizando una muestra de malta analizada 10 veces (Tabla 3). El desvío estándar, los valores máximos y mínimos, así como los límites de control fueron determinados a partir de los resultados.

Muestras de cebada fueron analizadas bajo la misma metodología que la malta (no se muestran los resultados).

También se ensayó la actividad endoproteolítica del mosto cervecero y de esta manera se pudo determinar el alcance del método (Gráfico 8).

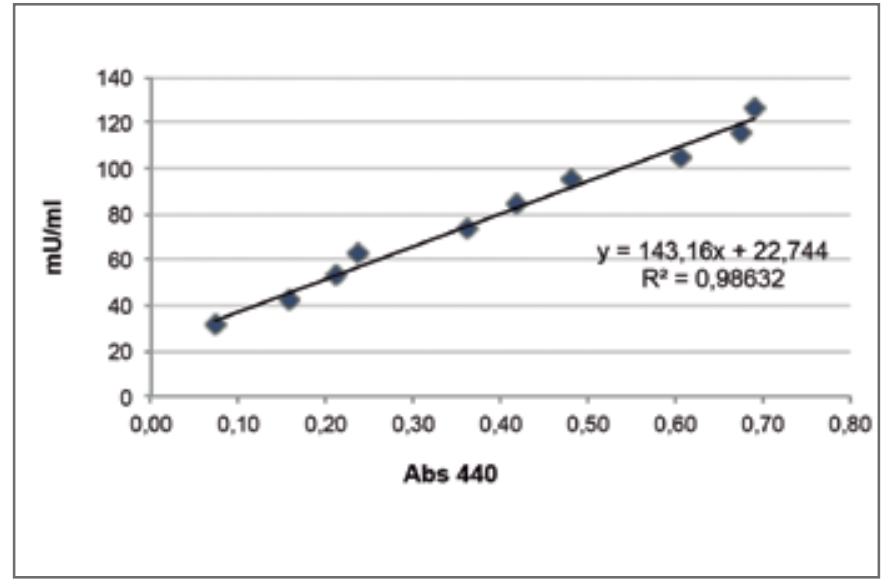

Gráfico 7. Curva de calibración de la enzima papaína utilizada como estándar. Las condiciones de reacción fueron: $1 \mathrm{mg} / \mathrm{mL}$; azocaseína al $2 \%, \mathrm{pH} 6,0$, adición de cisteína $10 \mathrm{mM}$ durante $30 \mathrm{~min}$ de reacción.

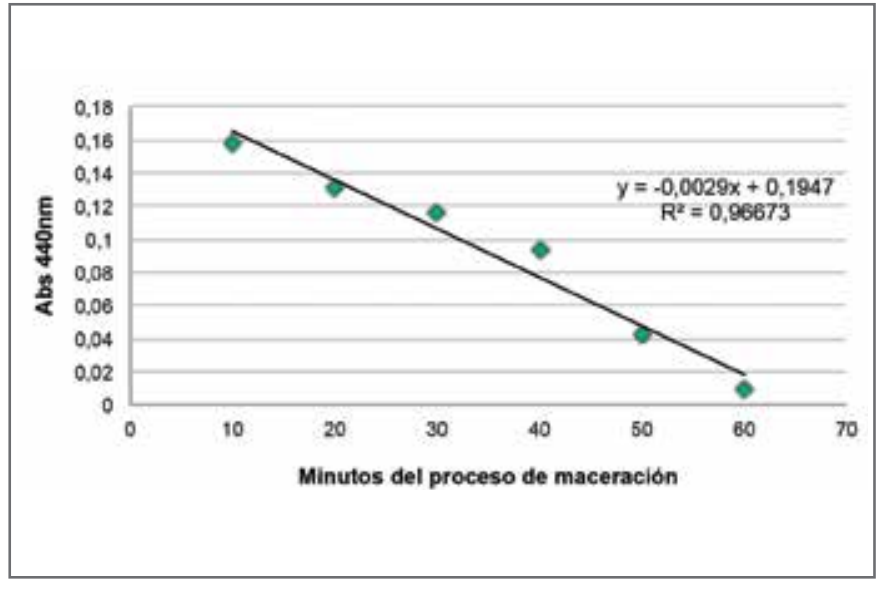

Gráfico 8. Alícuotas de mosto removidas a diferentes tiempos durante el mosto Congreso. Las condiciones de reacción fueron: azocaseína al 2\%, pH 6,0, adición de cisteína 10 mM durante 30 min de reacción.

\begin{tabular}{|c|c|c|c|c|c|}
\hline Tubo & $\begin{array}{c}\text { Submuestra } \\
\mathbf{1}\end{array}$ & $\begin{array}{c}\text { Submuestra } \\
\mathbf{2}\end{array}$ & Media & Diferencia & $\begin{array}{c}\text { mU/g } \\
\text { (base seca) }\end{array}$ \\
\hline 1 & 0,579 & 0,587 & 0,583 & 0,521 & 687 \\
\hline 2 & 0,590 & 0,598 & 0,594 & 0,532 & 701 \\
\hline 3 & 0,576 & 0,587 & 0,582 & 0,520 & 721 \\
\hline 4 & 0,576 & 0,585 & 0,581 & 0,519 & 709 \\
\hline 5 & 0,579 & 0,594 & 0,587 & 0,525 & 718 \\
\hline 6 & 0,589 & 0,587 & 0,588 & 0,526 & 724 \\
\hline 7 & 0,590 & 0,605 & 0,598 & 0,536 & 717 \\
\hline 8 & 0,581 & 0,580 & 0,581 & 0,519 & 737 \\
\hline 9 & 0,600 & 0,592 & 0,596 & 0,534 & 723 \\
\hline 10 & 0,606 & 0,619 & 0,613 & 0,551 & 707 \\
\hline \multicolumn{6}{|c}{ Variaciones entre extracciones } \\
\end{tabular}

Tabla 3. Test de reproducibilidad y repetibilidad con malta AC Metcalfe, utilizando azocaseína como sustrato. 


\section{Discusión}

Los estudios de linealidad entre la actividad proteolítica de la enzima papaína y el aumento de concentración de la enzima (desde $262 \mathrm{miliU} / \mathrm{mL}$ hasta $1115 \mathrm{miliU} / \mathrm{mL}$ ) utilizando el sustrato azogelatina para los tiempos de reacción estudiados mostraron una asociación lineal positiva. Estos resultados coinciden con los establecidos en trabajos de Jones et al. (2000, 2002 y 2003) en los cuales indicaban que para obtener una asociación lineal positiva debía existir una relación enzima:sustrato mayor a 1:1. La mejor relación que se determinó fue 1.32:1. Si bien se hicieron varios intentos por disminuir la absorbancia del blanco de reacción y establecer condiciones de reacción que permitieran obtener resultados consistentes y repetibles, esto no se logró. Tampoco se pudieron obtener resultados de la actividad endoproteolítica que reflejaran la calidad de las maltas analizadas. Por lo cual se considera que el sustrato azogelatina no permite obtener resultados consistentes de actividad endoproteolítica en muestras de malta.

En cambio, con los resultados logrados utilizando el sustrato azocaseína se obtuvieron blancos de reacción con valores de absorbancia bajos $(0,074)$ en comparación con los obtenidos con el sustrato azogelatina. También el sustrato azocaseína permitió detectar los cuatro tipos de endoproteasas que se encuentran en la cebada y ajustar de esta manera una metodología que haga posible la detección de la actividad de una manera consistente y repetible.

Los estudios de las enzimas puras a distintos niveles de $\mathrm{pH}$ permitieron demostrar que el tipo de endoproteasa que se encuentra más activo al pH del mosto cervecero $(6,00)$ es el tipo cisteín. Por esto se decidió utilizar la enzima papaína como estándar y realizar la curva de calibración que posibilitó obtener la ecuación para el cálculo de la actividad endoproteolítica.

Se pudo demostrar también que la metodología ajustada permite distinguir maltas de distintos tipos de calidad maltera, con lo cual es de esperar que tengan distinta actividad endoproteolítica. Las maltas 1 y 2 (Gráfico 8) son maltas que presentan mejor calidad maltera, mejor modificación durante el proceso de malteo y mayor valor de amino nitrógeno libre, por lo que era de esperar que presentaran una mayor actividad endoproteolítca en comparación con la malta 3. La malta 3 es una malta de baja calidad maltera, con bajos niveles de nitrógeno amínico libre, y esto se demostró con el bajo nivel de actividad endoproteolítca presentado.

La repetibilidad del método fue muy buena, con un coeficiente de variación de 2,0 para la variabilidad entre extracciones diferentes y un coeficiente de variación de 1,1 utilizando la misma extracción.

El alcance del método se determinó al analizar bajo la misma metodología muestras de cebada y mosto cervecero, además de la malta. Los resultados de actividad endoproteolítica del mosto fueron los esperables, ya que a medida que pasan los minutos del proceso de maceración la temperatura del macerado va aumentando de $45{ }^{\circ} \mathrm{C}$ a $70{ }^{\circ} \mathrm{C}$ y es esperable que la actividad enzimática disminuya, como se observó en el gráfico correspondiente.

\section{Conclusiones}

Se puso a punto el método para determinar la actividad endoproteolítica de la malta, cebada y mosto, en condiciones reductoras (adición de cisteína $10 \mathrm{mM}$ ), a pH 6,0 (pH del mosto), por $30 \mathrm{~min}$ de reacción, utilizando el sustrato azocaseína. Se lograron buenos niveles de exactitud y precisión bajo la metodología descrita. El tipo cisteína de las endoproteasas es el que principalmente se identifica en las condiciones definidas en el estudio, a pesar de ello, cambios en el pH y en las condiciones reductoras pueden ser ensayados para determinar los otros tres tipos de endoproteasas, aspartic, serin y metalo, como ya se demostró. Estudios en mayor profundidad se deberían realizar para optimizar las condiciones del método, de manera de determinar las otros tipos de endoproteasas que se encuentran en la cebada.

\section{Referencias}

- BRIGGS, D.E. Malt analyses. En: Malts and malting. London: Blackie Academic \& Professional, 1998. pp. 579-614.

- EBC ANALYSIS COMMITTEE. Analytica-EBC. 5ta. ed. Grundwerk: Fachverlag Hans Carl, Nüremberg. 1998, Ninth supplement to the fifth edition 2010. Official Method 4.5.1.

- JONES, B.L. The endoproteinases of barley and malt and their endogenous inhibitors. En: Tech. Q. Master Brew. Assoc. Am. 2008, 45:279-282.

- JONES, B.L. Endoproteases of barley and malt. En: Journal of Cereal Science. 2005a, 42:139-156

- JONES, B. L. The endogenous endoproteinase inhibitors of barley and malt and their roles in malting and brewing. En: Journal of Cereal Science. 2005b, 42:271-280.

- JONES, B.L.; BUDDE, A.D. The effect of reducing and oxidizing agents and $\mathrm{pH}$ on malt endoproteolytic activities and on malt mashes. En: Journal of Agricultural and Food Chemistry. 2003, 51:7504-7512.

- JONES, B.L.; MARINA C, L. The effect of mashing on malt endoproteolytic activities. En: Journal of Agricultural and Food Chemistry. 2002, 50:858-864

- JONES, B.L.; FONTANINI, D.; JARVINEN, M.; PEKKARINEN, A. Simplified endoproteinase assays using gelatin or azogelatin. En: Analytical Biochemistry. 1998, 263:214-220.

- JONES, B.L.; MARINAC, L.A.; FONTANINI, D. A quantitative study of the formation of endoproteolytic activities during malting and their stabilities to kilning. En: Journal of Agricultural and Food Chemistry. 2000, 48:3898-3905.

- KIHARA, M.; OKADA, Y.; SAITO, W.; KAWADA, N.; KANEKO, T.; ASAKURA, T.; ITO, K. QTL analysis for proteinase activity based on doubled-haploid progeny of standard Japanese and North American malting barley cultivars. En: Tech. Q. Master Brew. Assoc. Am. 2006, 43:15-18.

- KOEHLER, S.; HO, T.-H.D. Hormonal regulation, processing, and secretion of cysteine proteases in barley aleurone layers. En: The Plant Cell. 1990, 2:769-783.

- MEGAZYME INTERNATIONAL. Assay of endo-protease using AZOCASEIN. S-AZCAS 12/07 [En línea]. Wicklow: Megazyme International, 2007. [Consulta: 11 de noviembre de 2013]. Disponible en: http://secure. megazyme.com/files/BOOKLET/S-AZCAS 0712 DATA.pdf

- OSMAN, A.M. Barley and malt proteins and proteases. I. Highly degradable barley protein fraction (HDBPF), a suitable substrate for malt endoprotease assay. En: Journal of the Institute of Brewing. 2003, 109(2):135-141.

- PALMA, J.M.; SANDALIO, L.M.; CORPAS, F.J.; ROMEROPUERTAS, M.C.; MCCARTHY, I.; DEL RÍO, L.A. Plant proteases, protein degradation and oxidative stress: role of peroxisomes. En: Plant Physiol. Biochem. 2002, 40:521-530.

- POTOKINA, E.; PRASAD, M.; MALYSHEVA, L.; RÖDER, M. S.; GRANER, A. Expression genetics and haplotype analysis reveal cis regulation of serine carboxypeptidase I (Cxp1), a candidate gene for malting quality in barley (Hordeum vulgare L.). En: Funct. Integr. Genomics. 2006, 6:25-35.

- SCHMITT, M.R ; BUDDE A.D. Use of fluorogenic proteinase assays to examine protein mobilization in barley varieties and across populations. En: Tech. Q. Master Brew. Assoc. Am. 2007, 44:273-277.

- YANO, M.; TSUDA, H.; IMAI, T.; OGAWA, Y.; OHKOCHI, M. The effect of barley adjuncts on free amino nitrogen contents in wort. En: Journal of the Institute of Brewing. 2008, 114(3):230-238.

- ZHANG, N.; JONES, B.L. Characterization of germinated barley endoproteolytic enzymes by two-dimensional gel electrophoresis. En: Journal of Cereal Science. 1995a, 21:145-153.

- ZHANG, N.; JONES, B.L. Development of proteolytic activities during barley malting and their localization in the green malt kernel. En: Journal of Cereal Science. 1995b, 22:147-155. 